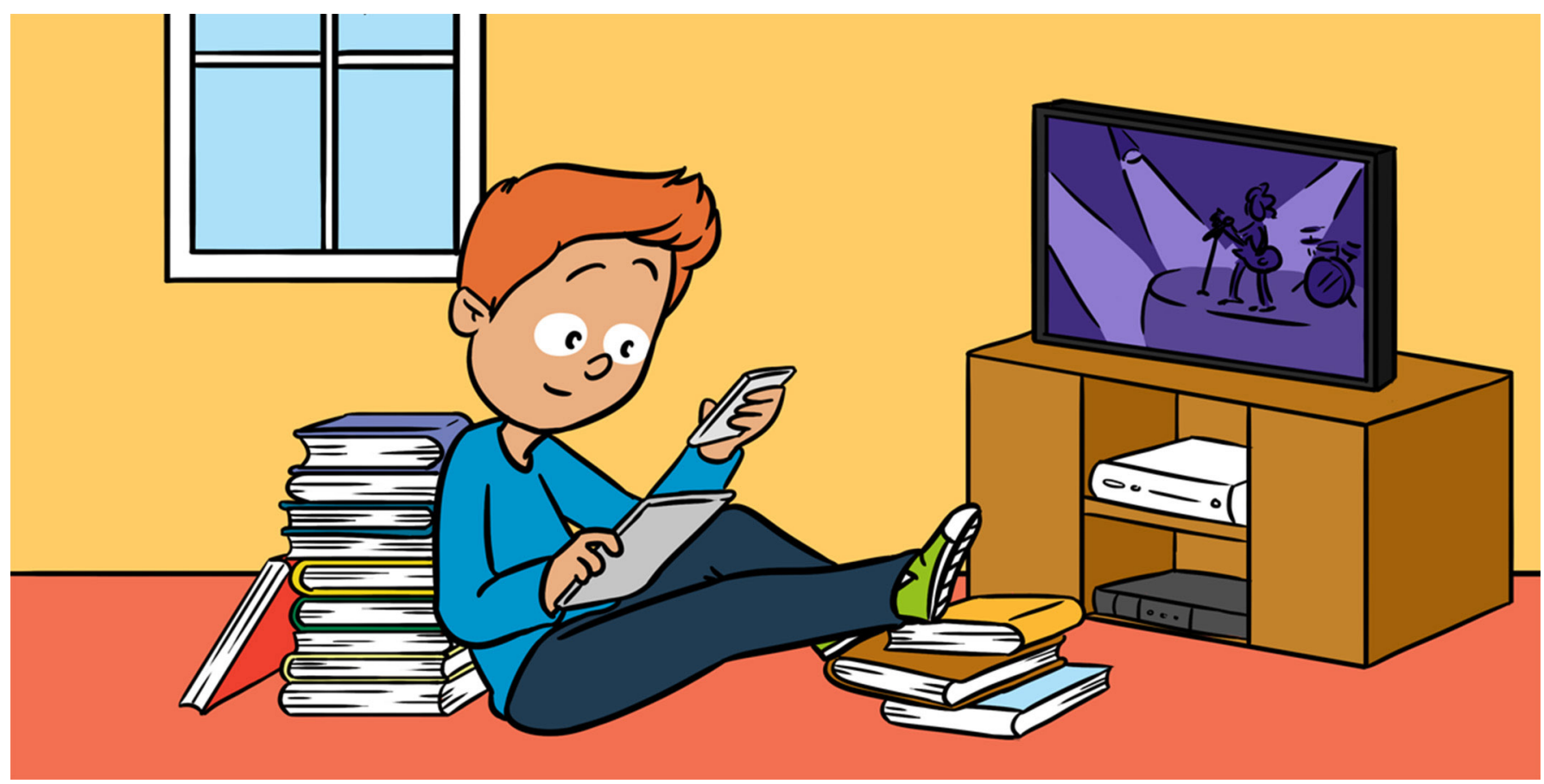

\title{
READING VS. PLAYING ON A TABLET: DO THEY HAVE DIFFERENT EFFECTS ON THE BRAIN?
}

\section{Tzipi Horowitz-Kraus*}

Educational Neuroimaging Center, Technion Israel Institute of Technology, Haifa, Israel

\section{YOUNG REVIEWERS:}

TABIB JUNIOR

$\mathrm{HIGH}$

SCHOOL

AGES: $12-13$
The school bell rang long ago, but Danny is still sitting in his chair, trying to finish copying from the board. "Why is this process so hard? Why does it take me so much longer to read than it takes my friends?" Danny is frustrated. The more he tries to read faster, the harder it is for him to understand what he is reading. Around the time when he finally finishes copying, his friends come back to the class from the break. Like $10-15 \%$ of the children in the world, Danny has dyslexia. Dyslexia is defined as difficulty in reading accurately or quickly and, most of the time; it affects the person's ability to understand what is read and to spell words correctly. The reading difficulty continues into adulthood and does not disappear, even though most adults with dyslexia find ways to "bypass" this difficulty, sometimes using text-tospeech software. Children and adults with dyslexia have different brain activity than do people who are good readers. They have lower activity in the brain area responsible for vision and identification of words [1, 2] and in another brain area responsible for attention and recognition of errors during reading [3]. A question could then be asked: is this 
reading difficulty strange or is it actually the ability to read that is magical? How did the human brain learn to read? And does the daily use of technology, which sometimes "bypasses" the need to make an effort to read, help us to learn to read or make it more difficult? This article will discuss these subjects.

\section{WHAT HAPPENS IN THE BRAIN WHEN WE READ?}

Reading is a relatively new human ability-about 5,000 years old. The Egyptians were among the first to use symbols to represent words within a spoken language, and they used drawings to transmit ideas via writing. As difficult as it is to draw each word in a language, it is still much easier to understand Egyptian hieroglyphs than to figure out what is written in an unfamiliar language. Today, 5,000 years later, we expect each child in first grade to immediately understand that the lines and circles that form letters have a unique sound corresponding to them. To do that, the brain has to rely on neural networks that were designed to perform other tasks, such as seeing, hearing, language comprehension, speech, attention, and concentration [4] (see Figure 1). Not only must our brain recruit these neural networks at the early age of five, but it also must do it at exactly the right time (for additional reading, see the article "The Reading Brain" in Frontiers for Young Minds). If one brain network joins the process a bit too late, a reading difficulty may arise, like the difficulty experienced in dyslexia or in other developmental disorders, like attention deficit hyperactivity disorder (ADHD). In brain imaging studies, which allow scientists to see how and where the brain is active in response to a specific stimulus, we try to examine at what age these brain areas (also called the "reading network")

Figure 1

Regions in the brain participate in reading Brain areas that take part in the reading process: attention, concentration, memory and other thinking areas (red), vision (green), and language (light blue). Dark blue areas are involved in hearing and yellow areas are involved with creating meaning. Taken from Horowitz-Kraus and Hutton, 2015 [4].

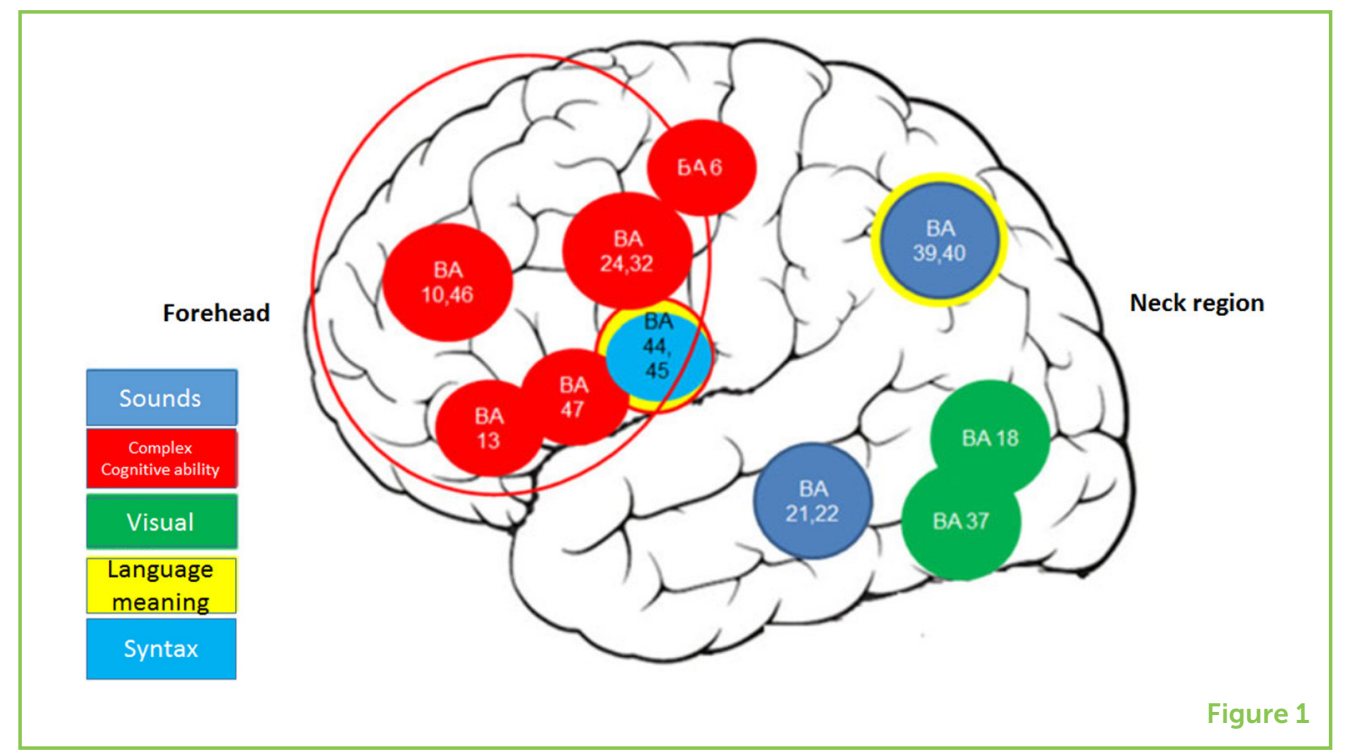




\section{ELECTRODES}

(ELECTRODE HAT)

Electrical wires connected to a sensor (on the scalp) to measure the electrical activity of the brain. "get ready" to read, even before the age of 5 . Then, we can tell which regions are active differently due to dyslexia. We can do that using an imaging tool such as functional magnetic resonance imaging (fMRI), which gives us a picture of the areas in the brain that become active when a specific task is performed. We can also image the brain using a special hat with some electrodes that measure electrical activity (a method called electroencephalography, EEG). These imaging tools are not hazardous and do not require anesthetics, and they can reveal, in real time, whether the brain of a child is "getting ready" to learn to read at a very young age.

Using these imaging tools on 5-years-old children, we found that, when children listen to stories, brain areas that are connected to language and understanding are active, as well as areas involved with vision [5]. The reason why vision areas are active while children do not actually see anything is that the children use imagination while they are listening to stories. What is using imagination if not "seeing" the story that you are hearing in your mind's eye? The same brain areas that are used for "imagination" during the hearing of a story (the green areas in Figure 1) are used at a later age for reading words. This is one of the reasons why it is important to regularly listen to stories at a young age, even before learning to read.

In another study, we found that the more the parent reads stories to a child and the more the child plays language and reading games at the age of three, the stronger the activation of the child's brain areas that are related to future reading [6]. We even found that it is possible to examine the child's brain at the age of four and improve the synchronization of the activity of the reading and language areas! (light blue area in Figure 1) [7].

If the neural network supporting reading already exists at such a young age, is it possible to "spoil" it? Or, alternatively, is it possible to "strengthen" it?

\section{DO SCREEN TIME AND READING TIME HAVE DIFFERENT EFFECTS ON THE BRAIN?}

We are currently living in spectacular technological times where we always have access to everyone, as well as access to information sources in one click. There is no need to read a book, because it is possible to watch a movie. There is no need to read long definitions in the encyclopedia because, it is possible to search the internet for a word 
and immediately get its meaning along with links to additional related information. Convenient? Perhaps, good for the brain? Not necessarily. Our research looks at this question.

\section{HOW DID WE TEST OUR QUESTION?}

Nineteen healthy children of ages 8-12 participated in this research, all English speakers. These children underwent an fMRI scan. The MRI device is a big magnet, with no radiation, which allows scientists to track the blood flow in the brain. The blood flow shows the active brain regions.

This means we can use $\mathrm{fMRI}$ to see which areas of the brain are activated while the children perform tasks that involve vision, attention, language processing, and additional skills. The children were asked to look at a screen with nothing on it other than the "+" sign. This is called a "resting state" task, and it allowed us to check the brain networks involved with vision, attention, and other brain functions when the children were "resting." The brain does not stop being active even when it is resting and studies have shown that it is possible to see that these brain networks are active during resting conditions. After completing the scan, the children were asked how much time they spend using screens during the week (including cellphones or tablets and watching movies or television) and how much time they spend reading (including newspapers, books, and any other reading materials). We performed a mathematical analysis of these data, including a test called a correlation check (see here) to see how screen-time and reading-time were related to the activation of brain areas involved with language ability, attention, memory, and vision. In other words, how do reading time and screen time relate to the synchronization of regions supporting reading?

NEGATIVE/POSITIVE CONNECTIVITY IN THE BRAIN

Coordinated or uncoordinated blood flow in different areas in the brain.

\section{WHAT DID WE FIND?}

Our results show that screen exposure time in children aged $8-12$ is followed by what we call a negative connectivity of the brain area responsible for reading words (black circle in Figure 2) with other brain areas responsible for vision, language, and concentration (blue circles in Figure 2B). Reading time, on the other hand, is followed by a positive connectivity of these areas (red circles in Figure 2A). In other words, the longer the screen exposure time is, the less coordinated the brain area responsible for reading words is with areas related to vision, language, attention, and concentration. In contrast, the longer the reading time is the more coordinated the area responsible for reading words is with these other brain areas. 
Figure 2

How do reading and screen time relate to brain connectivity?

(A) The dark circle represents the brain area responsible for reading words. Longer reading time showing greater connectivity with the reading words area (black circle) and with other areas responsible for attention,

concentration, vision, and language (red circles). (B) Longer screen time showing negative connectivity with area responsible for similar capabilities (blue circles) in Englishspeaking children aged 8-12. In this image, you are viewing the brain from the top down and the letters $L$ and $R$ indicate the left and right sides of the brain.
A.

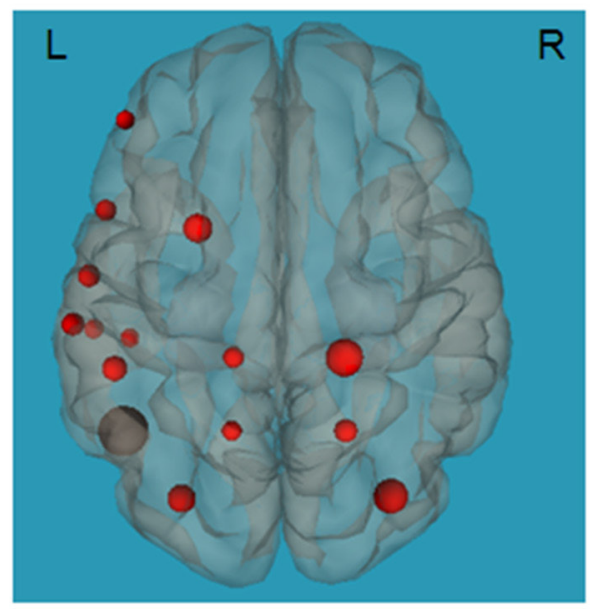

B.

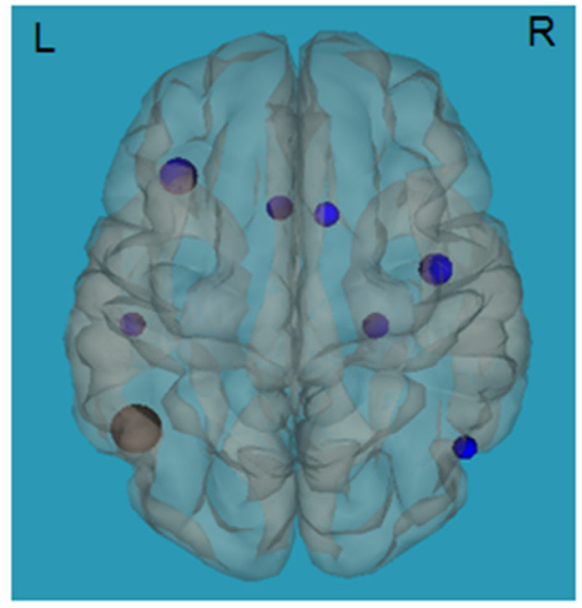

Figure 2

The results of the current research indicate that a longer reading time goes hand in hand with higher connectivity of additional areas related to learning and reading. In other words, the more time children spend reading books, the more coordinated the word reading area (Figure 1, in green) is with other brain areas involved in the learning and reading process. The longer the screen exposure time, the more active the word identification area is and the less active the learning and reading areas are. Watching a movie is not the same as reading a book. Is excessive screen time causing "degeneration" of brain areas that were developed during evolution to enable us to read? We still do understand the longterm consequences of frequent screen time. This question is extremely important to brain researchers all over the world. We know that screen time is increasing worldwide, and that the percentage of children having trouble learning due to attention and concentration difficulties or dyslexia is also rising. But it is still unclear whether these two things are connected. Studies examining the differences in brain activity after exposure to books vs. exposure to screens and to human voices vs. metallic (machine) voices are currently being researched. A point to ponder: the iPhone inventor, Steve Jobs, did not allow his children to use a tablet.

\section{CONCLUSION}

It is important to emphasize that this research only found a correlation or relationship, between reading time and screen time in relationship to brain activity. We do not know if the use of screens is actually harmful, or whether the decrease in reading books and the reduced exposure to written language explains the differences in brain activity 
that we saw in our study. In addition, it is not clear if brain activity in children with learning difficulties changes due to exposure to screens. Yet, we do know that the exposure to books and to reading has positive effects on brain activity in these children. Because the extensive exposure to technology in our daily lives is relatively new, the research on the correlation between this technology and brain development, in both children and adults, is only at its initial stages. Our brains are miraculous and adaptable, and constantly affected by external stimuli during our entire lives. Therefore, we assume that reading books and stories, and playing challenging thought games, will likely improve reading and learning abilities even in people who experience excessive screen time.

\section{ORIGINAL SOURCE ARTICLE}

Horowitz-Kraus, T., and Hutton, J. S. 2018. Brain connectivity in children is increased by the time they spend reading books and decreased by the length of exposure to screen-based media. Acta Paediatr. 107:685-93. doi: 10.1111/apa.14176

\section{REFERENCES}

1. Maisog, J. M., Einbinder, E. R., Flowers, D. L., Turkeltaub, P. E., Eden, G. F. 2008. A meta-analysis of functional neuroimaging studies of dyslexia. Ann $N$ Y Acad Sci. 1145:237-59. doi: 10.1196/annals.1416.024

2. Olulade, O. A., Flowers, D. L., Napoliello, E. M., Eden, G. F. 2013. Developmental differences for word processing in the ventral stream. Brain Lang. 125:134-45. doi: 10.1016/j.bandl.2012.04.003

3. Horowitz-Kraus, T., and Breznitz, Z. 2014. Can reading rate acceleration improve error monitoring and cognitive abilities underlying reading in adolescents with reading difficulties and in typical readers? Brain Res. 1544: 1-14. doi: 10.1016/j.brainres.2013.11.027

4. Horowitz-Kraus, T., and Hutton, J. S. 2015. From emergent literacy to reading: how learning to read changes a child's brain. Acta Paediatr. 104:648-56. doi: 10.1111/apa.13018

5. Horowitz-Kraus, T., Vannest, J. J., and Holland, S. K. 2013. Overlapping neural circuitry for narrative comprehension and proficient reading in children and adolescents. Neuropsychologia 51:2651-62. doi: 10.1016/j neuropsychologia.2013.09.002

6. Hutton, J. S., Horowitz-Kraus, T., Mendelsohn, A. L., DeWitt, T., and Holland, S. K. 2015. Home Reading Environment and Brain Activation in Preschool Children Listening to Stories. Pediatrics 136:466-78. doi: 10.1542/peds.2015-0359

7. Horowitz-Kraus, T., Hutton, J. S., Phelan, K., and Holland, S. K. 2018. Maternal reading fluency is positively associated with greater functional connectivity 
between the child's future reading network and regions related to executive functions and language processing in preschool-age children. Brain Cogn. 121:17-23. doi: 10.1016/j.bandc.2018.01.003

SUBMITTED: 24 October 2018; ACCEPTED: 15 November 2018; PUBLISHED ONLINE: 11 December 2018

EDITED BY: Idan Segev, Hebrew University of Jerusalem, Israel

CITATION: Horowitz-Kraus T (2018) Reading vs. Playing on a Tablet: Do They Have Different Effects on the Brain? Front. Young Minds 6:66. doi: 10.3389/frym.2018.00066

CONFLICT OF INTEREST STATEMENT: The author declares that the research was conducted in the absence of any commercial or financial relationships that could be construed as a potential conflict of interest.

COPYRIGHT (?) 2018 Horowitz-Kraus. This is an open-access article distributed under the terms of the Creative Commons Attribution License (CC BY). The use, distribution or reproduction in other forums is permitted, provided the original author(s) and the copyright owner(s) are credited and that the original publication in this journal is cited, in accordance with accepted academic practice. No use, distribution or reproduction is permitted which does not comply with these terms.

\section{YOUNG REVIEWERS}

\section{TABIB JUNIOR HIGH SCHOOL, AGES: 12-13}

We are a seventh grade, gifted class, at "Tabib" junior high school in Rishon LeZion (the fourth largest city in Israel). We are a small class, 13 boys and 6 girls (we went for quality over quantity). We are 13 years old and despite our young age, we were very critical while reviewing this article. We have learned new things from the review process and hope you enjoy the product. The review project was carried out with the help of the science mentor Dr. Yael Kuperman. This review is in memory of our beloved teacher, Yifat Rotstein Bsevitch, who sadly passed away recently. Yifat contributed a lot to our class achievements and to the positive atmosphere in it.

\section{AUTHOR}

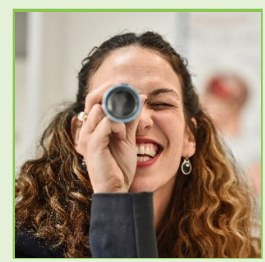

\section{TZIPI HOROWITZ-KRAUS}

I am an Assistant Professor of Pediatrics and Neuroscience and the Director of the Educational Neuroimaging Center at the Technion, Israel and the Scientific Director of the Reading and Literacy Discovery Center in Cincinnati Children's Hospital Medical Center in the US. In both labs, I focuses on brain activation related to complex cognitive abilities, language and reading development in typical and atypically developing children. *tzipi.horowitz-kraus@cchmc.org 